\title{
The ethics of resource allocation
}

\author{
Kenneth M Boyd Scottish Director, Society for the Study of Medical Ethics
}

\section{Author's abstract}

This commentary focuses on two moral values implied by the case study but not specified in the working party's conclusions, namely equitable treatment of the most vulnerable and the value of political government.

The moral of the Walkergate Hospital story, the working party state, is a confused one, but from the confusion they are able to extricate at least one lesson. Medicine and society seem to need dramatic and expensive symbols of the pricelessness of human life, but neither is prepared to meet the cost of regarding all human lives routinely in this way. Both therefore should accept the responsibilities their values imply and recognise that a distinction has to be made between expensive exceptions and a norm set at a lower level.

The working party have made a pertinent moral point. But as their lucid account of the realities of decision-making makes clear, their conclusion focuses on only one aspect of the ethics of resource allocation. In thinking about ethical questions, Professor Dorothy Emmet has remarked (I), it would be ideal if our moral judgment were like' $a$ white light showing clearly what action would be best in any situation': but in practice 'just as light coming through a prism is refracted into a spectrum of different colours, so our moral thinking shows us a range of different features, and attention can fasten now on one and now on another. And just as it is absurd to maintain that one colour in the spectrum is the only true, or even the truest form of light, so we must not make the mistake of assuming that one feature in the moral spectrum is the only true form of morality'. Anyone who has tried to study the ethics of resource allocation in health care, should, I think, recognise the appositeness of these words to that subject. Whether arguing from principles or attempting to expose values, the best-tested answers are scarcely fixed in their frames before further questions arise to set the moral kaleidoscope back into motion. The working party clearly have made out a persuasive

\section{Key words}

Ethics; resource allocation; medical ethics; values; equity; politics; moral complexity. moral argument for acceptance of the kind of distinction they propose as a means toward better and more rational resource allocation. But if we shift our focus of attention to other aspects of the Walkergate story, and in particular to two further moral values expressed in it, the argument becomes more complicated.

To uncover the first of these further moral values, which we could call that of equitable treatment of the most vulnerable, it is perhaps necessary to be rather more charitable than the working party are to the intentions of those involved in the acute specialties. While echoing all that the working party say about the need for trust among those working in the National Health Service (NHS), and while conceding that professional competitiveness and personal self-interest play their part in making everyone wish to defend his own, one need not deny that doctors defending their acute specialties are also defending the chances of survival of many individual patients who without their advocacy would die. In terms of their physical condition at least, these individual patients are among society's most vulnerable members; and in setting up and maintaining the NHS, it can be argued, society has set great store by the value of equitable treatment for them. The principle of equity means not that everyone should get the same treatment, but that different people should get different treatment, each in proportion to his or her needs. On this principle at least, the needs of those whose lives are at risk and can be saved by acute medical or surgical intervention, clearly have a strong claim on resources. The importance of this principle for our society is reflected in the thought, since 1948 part of our national mythology, that no consideration of class, or wealth, or intelligence or any other consideration except medical condition will stop the NHS from pulling out all the stops when an individual life is at risk and can be saved.

Recently, of course, this thought has been qualified, on the one hand by the suspicion that acute intervention, unrestrained by external controls, does not always serve the best interests of the most vulnerable, many of whom may only survive intervention for a short uncomfortable time, and on the other by the view that care and prevention are now more important demographic and epidemiological priorities. But these qualifications, however well founded, do not do away 
with the fact that without the advocacy of acute medicine, particular patients who would have lived to enjoy the benefits of medical or surgical intervention, will die. The fact that other values or principles are involved - or even that the same principle is concomitantly being offended against in the case of chronically ill or geriatric patients - does not invalidate the principle of equity in the case of these particular vulnerable members of society. Thus if that principle is important to society - if maintaining it is in fact one of the moral purposes of the NHS - then there may well be reasons why the public are and should be unwilling to accept, in NHS treatment, the kind of unfairness which, as the working party rightly point out, 'is commonly accepted in other areas of life'. If the kind of distinction between exceptions and the norm proposed by the working party were generally accepted and more widely adopted than it already is, it would be possible to argue, of course, that equitable treatment would not be denied to those whose medical condition (and perhaps geographical location) was appropriate to the allowed exceptions. But from the point of view of a doctor in a threatened acute specialty, this consideration, together with all the utilitarian and for that matter other equity arguments, would and should not remove the fact that the proposed distinction offended against the principle of equity in the case of many of his own patients. He might also want to argue, in psychological rather than ethical terms, that implementation of the proposed distinction might reduce the chances in the lottery of medical advance of many more patients, by reducing the creative tension between aspiration and achievement in relation to both equity and medical excellence in the NHS. That argument however, would have to be assessed on empirical grounds, if it could be assessed at all.

Equitable treatment in the case of these particular patients then may be a value to which it is important that the NHS should give symbolic expression. But even if it is denied that this is a moral purpose of the NHS, or if it is argued that the principle of equity should also be applied to patients outside the acute sector, the principle itself and its application to the first set of patients remains valid. The point here, in other words, is that what society is faced with in this aspect of the ethics of resource allocation, is a moral dilemma which cannot be resolved without offending against one value or the other. Adopting the distinction between exceptions and the norm as an organising principle based on what society values, moreover, is unlikely to lead to better and more rational decisionmaking as long as society, and doctors in particular, continue to value equitable treatment of the patients discussed.

Whether doctors in particular should, or can, cease to value equitable treatment of these particular patients is of course related to the values of the doctor-patient relationship. Discussion of that question would shake up the moral kaleidoscope further, but for the present purpose it may be more germane to try to uncover a second additional value from the Walkergate story, $\mathrm{a}_{\mathrm{m}}$ value which for the present purpose we might call that of political government. In this case the focus of atten-त्र tion can be shifted away from those who may benefit: from or be harmed by the proposed exception/normon distinction, to those who have to decide whether ito should be accepted and how it should be interpreted.

In discussing implementation of the distinction, the working party suggest that 'administrators, with a more distant view (than individual doctors) ought to be able to distinguish between what it is possible to maintain as ${ }^{\text {s }}$ a norm and what belongs to the category of the excep- $-\overrightarrow{0}$ tional'. In commending the distinction however, the $\overrightarrow{-}$ working party seem to suggest that its moral persua- $-\bar{N}$ siveness lies in getting medicine and society to face up to the responsibilities of their conflicting wishes. $\Phi$ Clearly someone as informed and impartial as possible. is needed to spell out these responsibilities and ad-i ministrators may have the necessary attributes. But if ${ }^{\circ}$ the working party's hope, that the distinction will hold? as an organising principle, is to be realised, the role ${ }^{-}$ they seem to suggest for administrators presents both practical and moral difficulties.

The practical difficulties involved are probably too well known to need much discussion here. The kind of ${ }_{\infty}^{\circ}$ situation in which the distinction would have to be implemented would be characterised by most of the financial and other pressures well illustrated in the Walkergate story. Under such pressures ad- $-\frac{\partial}{0}$ ministrators would almost inevitably be forced back upon bureaucratic interpretations of the distinction. In $\mathbb{Q}$ another recent case (2), for example, a Scottish Health $\stackrel{\circ}{\Rightarrow}$ Board declined to provide joint funding (with the socialo work authorities) of a community psychiatry day centre, on the grounds that the centre appeared to fulfil 'a social rather than a medical function' and that it 'could open the floodgates if the grey area between the social and the medical were breached - every group whose work had some relevance to health could apply 3 . for money at a time when cash is short'. From the administrative point of view such clear-cut distinctions 3 are necessary to hold the line. But the administrators'o distinctions often appear unreasonable to those affected by them. A critic of the health board just men-o tioned remarked of its decision 'In times of limited resources they feel they must shove these resources $N$ into a clearly defined "illness world". This is not justn economically short-sighted, it's a viewpoint that ignores people's experiences, their own feelings and ${ }^{\mathcal{E}}$ wishes'. As this kind of response indicates, administrative implementation of categories designed to을 rationalise decision-making, far from helping doctors $\cong$ and society face up to their responsibilities, may serve $e_{-}^{-}$ only to help them evade responsibility by simply blaming the bureaucrats.

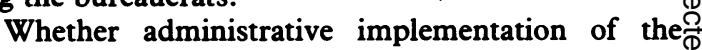
working party's distinction would in practice defeat its $\cong$ moral purpose, however, is another matter which in? the end could only be assessed empirically. But in ethical terms the difficulty of leaving implementation 
to administrators would seem to be indicated by what the working party write earlier in their study about the fact that 'decisions arise out of complicated interactions, and it is difficult to see how they could do otherwise in a democratic society'. In the light of what has already been said about the NHS giving symbolic expression to what is valued in the public mind, this remark raises the question of whether determination of priorities by democratic political government is not also a principle equally important to those discussed. Certainly, in a democratic society, political participation in decision-making is the practical expression of an important value. This is, moreover, a value which society may wish to maintain even at the cost of those better and more rational decisions which more farseeing administrators may prefer. Indeed this may be the most profound message of the Walkergate story.

The value of political government then may well be in conflict with the principle which the working party argue for in their conclusions; and since political decisions, no less than administrative, ultimately exclude some people from the benefits (including life-saving benefits) of the NHS, it may also be in conflict with the value of equitable treatment of the most vulnerable. But whichever way decisions are taken, scarcity of resources is a basic fact of human life and someone, perhaps many, will inevitably be unfairly treated. Political methods of resource allocation, as Calabresi and Bobbitt remark in their classic study of the subject (3), "can take into account social desire. But they do so at the cost of being substantially unable to distinguish, and give effect to, individual desires'. In this, they have the opposite effect to market methods of resource allocation which are able to give effect to the individual desires of those who can afford them, but are indifferent to what society as a whole may wish. In this connection it may be noted that the working party's conclusions are based on the assumption, largely unchallenged since 1948 , that the ballot box gives the public the last word on resource allocation decisions in British health care. More recently however, the pressures of global political economy may have begun to take decisions about the most expensive areas of medical advance out of the hands of elected government, so that progress in areas like heart transplantation (insofar as this is dependent on the provision of funds) may be determined by market rather than political decisions.

What seems to emerge then from this attempt to uncover further values from the Walkergate story, is the fact of fairly basic conflict between a number of different relevant values, each of which is and, it could be argued, should be, important to society. In the study already referred to, Calabresi and Bobbitt argue that no known method of resource allocation, nor any refinement of these, is able to succeed without offending against some value which society holds dear and for which a reasonable moral argument can be made out. The market, for example, not only is indifferent to many of society's wishes, but also too clearly puts a price on human life, which society wishes to regard as priceless; political allocation not only is indifferent to what many individuals wish, but too clearly involves the State in deciding 'that some people are not equal to others, or that some lives are not worth saving' (3). Both approaches, in other words, offend in some way against the value of human life or the principle of equity. A further approach, that of allocation by some kind of lottery, offends against equity again (in the name of a simplistic ideal of equality), as well as against both individual and social desires, and by the very choice of a lottery undermines the claim that human life is priceless. Despite the moral shortcomings of these different approaches however, society continues to employ one or another or some refinement or combination of them, without acknowledging fully their moral cost. But this also, Calabresi and Bobbitt argue, is to offend against an important value, namely that of honesty. If that value also is to be defended, they suggest, society has no option but to continue moving from one approach to another in ways which 'reaffirm the most threatened basic value and thereby seek to assure that its function as an underpinning of the society is not permanently lost'. In order to avoid totalitarianism on the one hand and the total rejection of some hitherto basic value on the other, 'a moral society must depend on moral conflict as the basis for determining mortality' (4).

The apparent conflict between the different values disclosed by the Walkergate story thus may be more hopeful than appears at first sight, however much despair such/a messy/business/may cause administrators anxious to assign priorities at a practical level or ethical theorists anxious to do something analogous at the level of values and principles. In developing the notion of the moral prism mentioned earlier, Professor Emmet writes that there is 'no a priori harmonious ordering of priorities' between the different features of the moral spectrum around which in turn we arrange our thinking about how we should act: 'conflict between them must be allowed for on the theoretical level as well as suffered on the practical one' (5). The task, she suggests, is to learn to become 'able to live with moral complexity' (6). In the case of the working party's conclusions, this probably means that the validity of their distinction between exceptions and the norm can only be accepted if the unfairness it involves continues to be seen, unblinkingly, as morally unacceptable. The practical consequences of such a moral view do nothing to make decision-making any easier.

\section{References}

(1) Emmet D. The moral prism. London: Macmillan, '79: I.

(2) Nelson S. Care or 'cure' for victims of mental illness. The Scotsman 1982 Sept 3: I I (cols I-8).

(3) Calabresi G, Bobbitt P. Tragic choices. New York: W W Norton, 1978: 145 .

(4) See reference (3) 198.

(5) See reference (I) 16.

(6) See reference (I) 158. 